\title{
ANALISIS KELAYAKAN DAN MODEL PENGEMBANGAN USAHA KERUPUK IKAN DENGAN PENDEKATAN ENTREPRENUERIAL MARKETING
}

\author{
FEASIBILITY ANALYSIS AND DEVELOPMENT MODEL BUSINESS FISH \\ CRACKER WITH ENTREPRENUERIAL MARKETING APPROACH \\ Lili Winarti ${ }^{1)}$, Sri Herlina ${ }^{1)}$ 'Rokhman Permadi ${ }^{1}$ ) \\ Agribisnis,Fakultas Pertanian ${ }^{1)}$, Universitas Darwan Ali \\ E-mail: liliwinarti14@gmail.co.id
}

\begin{abstract}
ABSTRAK
Tujuan dari penelitian ini adalah menganalisis kelayakan finansial, sensitivitas usaha, serta menganalisis model pengembangan usaha pengolahan kerupuk ikan di Kabupaten Seruyan. Penelitian ini dilaksanakan mulai Bulan Maret sampai dengan Juli 2018, menggunakan data primer dengan metode sensus pada seluruh pengusaha kerupuk ikan di Kabupaten Seruyan. Kelayakan finansial dalam usaha pembuatan kerupuk ikan ini dianalisis menggunakan beberapa kriteria investasi yaitu Net Present Value, Internal Rate of Return, Payback Period, Net B/C Ratio. Sensitifitas usaha dianalisis dengan menggunakan switching value, sedangkan model pengembangan usaha di analisis menggunakan PLS SEM. Berdasarkan hasil penelitian bahwa usaha kerupuk ikan di Kabuapten Seruyan layak untuk di usahakan berdasarkan 4 kriteria investasi yang digunakan dengan nilai NPV sebesar Rp 192.357.2999,43, IRR sebesar 60,94\%, Net B/C sebesar 2,76 dan pay back period sebesar 3 tahun 18 hari. Adapun hasil analisis sensitifitas menunjukkan penurunan harga jual lebih sensitive jika dibandingkan dengan penurunan harga bahan baku, dan untuk kenaikan harga bahan baku batas tertinggi sebesar 37,80\% dan untuk penurunan harga jual kerupuk batas terendah sebesar $24,30 \%$, dan berdasarkan analisis model pengembangan usaha (Entrepreneurial Marketing) diketahui bahwa Entrepreneurial marketing berpengaruh sangat signifikan ( $p$ value 0,000 ) terhadap pengembangan usaha kerupuk ikan di Kecamatan Seruyan Hilir Kabupaten Seruyan.
\end{abstract}

Kata kunci: Kelayakan Finansial, Entrepreneurial Marketing, Model, Pengembangan Usaha, Kerupuk Ikan.

\section{ABSTRACT}

The purpose of this study was to analyze financial feasibility, business sensitivity, and analyze the development model of fish cracker processing business in Seruyan District. This research was conducted from March to July 2018, using primary data by census method for all fish cracker entrepreneurs in Seruyan District. Financial feasibility in the fish cracker manufacturing business was analyzed using several investment criteria, namely Net Present Value, Internal Rate of Return, Payback Period, Net B / C Ratio. Business sensitivity is analyzed using switching value, while business development models are analyzed using PLS SEM. Based on the results of the study that the fish cracker business in Seruyan Regency is worthy of effort based on 4 investment criteria used with NPV value of Rp 192,357,2999.43, IRR of 60.94\%, Net B / C of 2.76 and pay back period for 3 years 18 days. The sensitivity analysis results show a decrease in selling prices more sensitive than the decrease in raw material prices, and for the increase in raw material prices the highest limit is $37.80 \%$ and for the decline in the selling price of crackers the lowest limit is $24.30 \%$, and based on analysis of development models business (Entrepreneurial Marketing) it is known that Entrepreneurial marketing has a very significant effect ( $p$ value 0,000) on the development of fish cracker business in Seruyan Hilir District Seruyan District.

Kata kunci : Financial feasibility, Entrepreneurial Marketing, Models, business development, Fish Cracker. 


\section{PENDAHULUAN}

Kabupaten Seruyan merupakan daerah perairan yang secara geografis memiliki wilayah laut dengan panjang garis pantai $\pm 100 \mathrm{Km}$, dibelah oleh Sungai Seruyan yang membentang dari Hulu (Kecamatan Seruyan Hulu) mengalir sampai ke muara laut (Kecamatan Seruyan Hilir) sepanjang \pm $350 \mathrm{Km}$ (Badan Pusat Statistik
Kabupaten Seryan, 2017). Sebagai daerah perairan, Kabupaten Seruyan memiliki potensi yang besar di bidang perikanan, baik perikanan darat atau perikanan laut yang penyebarannya hampir di seluruh kecamatan. Tabel 1 menunjukkan angka produksi perikanan darat dan laut yang dihasilkan oleh Kabupaten Seruyan pada Tahun 2016, dimana angka produksi mencapai 15.332 ton basah.

Tabel 1. Produksi Perikanan menurut Kecamatan di Kabupaten Seruyan (ton basah)

\begin{tabular}{lrrr}
\hline \multirow{2}{*}{ Kecamatan } & \multicolumn{2}{c}{ Produksi (ton) } & \multirow{2}{*}{ Jumlah } \\
\cline { 2 - 3 } & $\begin{array}{c}\text { Perikanan umum } \\
\text { (darat) }\end{array}$ & \multicolumn{1}{c}{ Perikanan laut } & $6.554,29$ \\
\hline Seruyan Hilir & 2.372 & $4.182,29$ & $2.387,30$ \\
Danau Sembuluh & $2.387,30$ & - & 618 \\
Hanau & 618 & - & 271,90 \\
Seruyan Tengah & 271,90 & - & 190,30 \\
Seruyan Hulu & 190,30 & - & $3.891,71$ \\
Seruyan Hilir Timur & $2.099,30$ & $1.792,41$ & 627 \\
Seruyan Raya & 627 & - & 384,10 \\
Danau Seluluk & 384,10 & - & 225 \\
Batu Ampar & 225 & - & 182,40 \\
Suling Tambun & 182,40 & - & $\mathbf{1 5 . 3 3 2}$ \\
Seruyan & $\mathbf{9 . 3 5 7 , 3 0}$ & $\mathbf{5 . 9 7 2 , 7 0}$ & \\
\hline
\end{tabular}

Sumber: Dinas Kelautan dan Perikanan Kabupaten Seruyan, 2017.

Besarnya potensi perikanan yang dimiliki diharapkan dapat menciptakan lapangan pekerjaan khususnya di bidang industri kecil dan industri rumah tangga (home industry) pengolahan hasil perikanan. Selain sebagai sumber lapangan pekerjaan, pengolahan ikan pada dasarnya memiliki fungsi untuk memaksimalkan manfaat hasil tangkapan, meningkatkan nilai tambah ekonomi dan memperpanjang daya tahan simpanan, sehingga hasil produksinya dapat mempengaruhi keadaan sosial ekonomi nelayan dan masyarakat sekitar pada umumnya.

Jika dibandingkan dengan potensi hasil produksi perikanan (darat maupun laut) yang dimiliki, nampaknya industri pengolahan yang ada di Kabupaten Seruyan belum optimal dalam menampung semua potensi produksi yang ada. Dari beberapa jenis industri pengolahan ikan, hanya industri pengolahan kerupuk yang memiliki tingkat produksi paling tinggi (36,37\% dari total volume produksi berbagai jenis olahan). Sebaran industri Pengolahan kerupuk ikan di Kabupaten Seruyan dapat 
Tabel 2. Jumlah Industri Kecil dan menengah (IKM) Kecamatan Seruyan Hilir Kabupaten Seruyan.

\begin{tabular}{|c|c|c|c|c|}
\hline No. & Nama Sentra & & Lokasi & Produk \\
\hline 1 & Kerupuk Umi Kalsum & & Kuala Pembuang I & Kerupuk ikan \\
\hline 2 & Kerupuk Ersyam & & Kuala Pembuang I & Kerupuk ikan \\
\hline 3 & Kerupuk Mama Sandy & & Kuala Pembuang I & Kerupuk ikan \\
\hline 4 & Kerupuk Ikan Rexsa & & Kuala Pembuang I & Kerupuk ikan \\
\hline 5 & Kerupuk Ikan Dahlia & & Kuala Pembuang I & Kerupuk ikan \\
\hline 6 & Kerupuk Mama Hesti & & Kuala Pembuang II & Kerupuk ikan \\
\hline 7 & Kerupuk Mama Erwin & & Kuala Pembuang II & Kerupuk ikan \\
\hline 8 & Kerupuk Mama Ema & & Kuala Pembuang II & Kerupuk ikan \\
\hline 9 & Kerupuk Mama Fajri & & Kuala Pembuang II & Kerupuk ikan \\
\hline 10 & Kerupuk Mama Tara & & Kuala Pembuang II & Kerupuk ikan \\
\hline 11 & Kerupuk Mama Zaki & & Kuala Pembuang II & Kerupuk ikan \\
\hline 12 & Kerupuk Ikan Aurora & & Kuala Pembuang II & Kerupuk ikan \\
\hline 13 & Kerupuk Ikan Saidah & & Kuala Pembuang II & Kerupuk ikan \\
\hline 14 & Kerupuk Hj. Asih & & Kuala Pembuang II & Kerupuk ikan \\
\hline 15 & Kerupuk Mama Riyan & & Kuala Pembuang II & Kerupuk ikan \\
\hline 16 & Kerupuk Ikan Rada & & Kuala Pembuang II & Kerupuk ikan \\
\hline 17 & $\begin{array}{l}\text { Kerupuk Ikan Putra } \\
\text { Kalsum }\end{array}$ & Umi & Kuala Pembuang II & Kerupuk ikan \\
\hline
\end{tabular}

Sumber: Dinas Koperasi, UKM, Perindustrian dan Perdagangan Kabupaten Seruyan. 2017.

Pengembangan industri kecil dan rumah tangga terutama pngolahan kerupuk ikan perlu dilakukan di Kabupaten Seruyan. Namun dalam pengembangannya, terdapat sejumlah permasalahan yang dihadapi oleh pelaku usaha seperti permasalahan teknologi dan peralatan, kewirausahaan dan keahlian, inovasi produk dan usaha, pembukuan atau catatan keuangan, standardisasi, aksesibilitas terhadap sumber daya produktif, pemasaran, serta pembiayaan.

Kemampuan pembukuan dan pencatatan keuangan merupakan suatu hal yang tidak kalah penting dalam menjalankan usaha. kebanyakan para pengusaha kerupuk ikan di Kabupaten Seruyan tidak mengetahui secara rinci bagaimana perhitungan ekonomi dari usaha yang mereka jalankan, sehingga kelayakan usaha yang dilakukan tidak berdasarkan pada perhitungan yang sebenarnya. Padahal pengukuran kelayakan terutama kelayakan finansial merupakan alat ukur yang dapat digunakan untuk melihat apakah usaha yang akan dijalankan dapat memberikan keuntungan atau tidak dan layak secara ekonomi.

Permasalahan lainnya yang juga sering dihadapi oleh pengusaha kerupuk ikan yaitu pemasaran. Kebanyakan kerupuk ikan yang diproduksi dipasarkan kepada konsumen lokal, hanya pengusaha tertentu yang mampu mengakses pasar ke luar daerah. Kenyataan di lapangan 
pengusaha juga menghadapi produkproduk kerupuk ikan dari daerah lain, sehingga dengan kondisi tersebut membuat tidak banyak masyarakat yang ingin berusaha di bidang pengolahan kerupuk. Adapun penelitian ini meliputi: 1) Menganalisis kelayakan finansial usaha pembuatan kerupuk ikan di Kabupaten Seruyan, 2) Menganalisis Sensitifitas usaha pengolahan kerupuk ikan di Kabupaten Seruyan, dan Merumuskan model pengembangan industri pengolahan kerupuk ikan di Kabupaten Seruyan dengan pendekatan entrepreneurial marketing.

\section{METODE PENELITIAN}

\section{Lokasi, Waktu, dan Jenis Data Penelitian}

Penelitian ini dilaksanakan di Kabupaten Seruyan khususnya di Kecamatan Seruyan Hilir Propinsi Kalimantan Tengah. Pelaksanaan penelitian dimulai dari bulan Maret 2018 sampai dengan Juli 2018, yaitu mulai dari tahap pengumpulan data, pengolahan dan analisis sampai dengan penyusunan laporan penelitian. Data yang dikumpulkan dalam kegiatan ini meliputi data primer dan data sekunder. Data primer bersumber langsung dari responden dalam hal ini pengusaha kerupuk ikan yang diambil melalui metode sensus, yaitu semua populasi pengusaha kerupuk ikan yang terdapat di Kabupaten Seruyan diambil datanya. Sedangkan untuk data sekunder diperoleh dari instansi atau lembaga yang ada kaitannya dengan penelitian ini, seperti Dinas Kelautan dan Perikanan (DISLUTKAN), Dinas Perdagangan Perindustrian dan Koperasi (DISPERINDAGKOP), Badan Pusat Statistik (BPS) Kabupaten Seruyan Propinsi Kalimantan Tengah.

Data yang digunakan dalam penelitian ini dikumpulkan dengan cara melakukan wawancara dan memberikan daftar pertanyaan (kuisioner) secara langsung kepada responden, sedangkan data-data penunjang lainnya diperoleh dengan melakukan studi pustaka pada instansi terkait seperti Laporan Tahunan Disperindagkop, Laporan Tahunan Dinas Kelautan dan Perikanan, Seruyan Dalam Angka Badan Pusat Statistik, dan beberapa publikasi lainnya yang dianggap relevan.

\section{Analisis Data}

Analisis kelayakan aspek finansial dalam usaha pembuatan kerupuk ikan ini menggunakan beberapa kriteria investasi, yaitu: Net Present Value (Nilai Bersih Sekarang), Net Benefit and Cost Ratio (Net B/C Rasio), Internal Rate of Return (IRR), jangka waktu pengembalian 
(Payback Period). Selanjutnya untuk melihat kembali hasil analisis suatu kegiatan investasi atau aktivitas ekonomi terhadap ada tidaknya perubahan apabila terjadi kesalahan atau adanya perubahan di dalam perhitungan biaya atau manfaat maka dilakukan analisis Switching Value (Analisis Sensitifitas). Analisis ini dilakukan pendekatan duan dua parameter: Parameter 1, Apabila terjadi kenaikan harga bahan baku ikan 5\%, 10\% dan $15 \%$, parameter 2, dan Parameter 2, jika terjadi penurunan harga jual kerupuk ikan 5\%, $10 \%$ dan $15 \%$.

Sementara model pengembangan usaha kerupuk ikan dengan pendekatan Entrepreneurial Marketing dianalisis menggunakan model persamaan struktural berbasis varians dengan pendekatan parsial (partial least square). Analisis PLS SEM digunakan untuk mengetahui pengaruh Entrepreneurial Marketing terhadap pengembangan usaha. Terdapat tujuh dimensi Entrepreneurial Marketing dalam penelitian ini yaitu dimensi kemampuan berinovasi (innovativeness), proaktif (proactiveness), fokus pada peluang (opportunity focus), pemanfaatan sumberdaya (resource leveraging), pengabilan resiko yang terukur (calculated risk taking), intensitas konumen (customer intensity), dan penciptaan nilai (value creation). Pada masing-masing variabel dilakukan uji pengaruh langsung terhadap perkembangan usaha.

Adapun hipotesis dalam penelitian ini adalah:

$\mathrm{H} 1$ :Calculate risk berpengaruh terhadap Entrepreneurial Marketing

$\mathrm{H} 2$ :Costumer intensity berpengaruh terhadap

Entrepreneurial Marketing

H3 :Innovativeness berpengaruh terhadap Entrepreneurial Marketing

H4 :Oppurtunity focus berpengaruh terhadap

Entrepreneurial

Marketing

H5 :Proactiveness berpengaruh terhadap Entrepreneurial Marketing

H6 :Resourse laveranging berpengaruh terhadap

Entrepreneurial

Marketing

H7 :Value creation berpengaruh terhadap Entrepreneurial Marketing

H8: Entrepreneurial Marketing berpengaruh terhadap pengembangan usaha (PU)

\section{HASIL DAN PEMBAHASAN}

\section{Karakteristik pengrajin kerupuk ikan}

Pengrajin kerupuk ikan yang digunakan dalam penelitian ini adalah para pengrajin kerupuk yang masih aktif dalam menjalankan usahanya dalam 
pengolahan kerupuk ikan. Adapun aspek karakteristik di dalam penelitian ini meliputi umur, pendidikan, dan lama usaha pengolahan kerupuk ikan.

Tabel 3. Karakteristik Pengrajin Kerupuk Ikan

\begin{tabular}{|c|c|c|}
\hline Karakteristik & Jumlah (orang) & Persentase $(\%)$ \\
\hline \multicolumn{3}{|l|}{ Umur (tahun) } \\
\hline$<30$ & 2 & 11,11 \\
\hline $30-40$ & 6 & 33,33 \\
\hline$>40-50$ & 5 & 27,78 \\
\hline $40>50$ & 5 & 27,78 \\
\hline \multicolumn{3}{|l|}{ Pendidikan } \\
\hline SD / Sederajat & 9 & 50.00 \\
\hline SMP / Sederajat & 2 & 11,11 \\
\hline SMU / Sederajat & 3 & 16,67 \\
\hline Sarjana / S1 & 4 & 22,22 \\
\hline \multicolumn{3}{|c|}{ Lama Usaha (tahun) } \\
\hline $1-3$ & 5 & 27,78 \\
\hline $3-6$ & 2 & 11,11 \\
\hline $6-9$ & 1 & 5,56 \\
\hline $9-12$ & 3 & 16,67 \\
\hline$>12$ & 7 & 38,89 \\
\hline Total & 18 & 100 \\
\hline
\end{tabular}

Sumber: Data Primer(diolah), 2018.

Mayoritas pelaku usaha atau pengrajin kerupuk ikan di dominasi oleh kelompok usia 30-40 tahun, hal ini menunjukkan pelaku usaha berada dalam usia yang produktif dalam bekerja, selain itu juga factor umur akan mendukung pelaku usaha dalam menjalankan usahanya dari proses penyiapan bahan baku, pengolahan sampai pada pemasaran kerupuk ikan yang mereka hasilkan. Pada usaha pengolahan kerupuk ikan ini, tidak memerlukan tingkat pendidikan yang tinggi, karena berdasarkan hasil wawancara tingkat pendidikan pada usaha pengolahan kerupuk ikan ini di dominasi oleh Sekolah Dasar (SD) yaitu sebesar 50,00\%, karena usaha pengolahan kerupuk ikan di tempat penelitian menjalankan usaha warisan dari orang tua mereka sebelumnya dengan pengalaman yang cukup dalam proses pengolahan kerupuk ikan. Karekteristik berdasarkan lama usaha kerupuk ikan yang dijalankan pelaku usaha mayoritas sebesar $38.89 \%$, hal ini mengindikasikan bahwa pelaku usaha memiliki pengalaman yang cukup banyak dalam menjalankan usahanya.

\section{Analisis Kelayakan Usaha}

Analisis kelayakan merupakan salah satu cara untuk menilai investasi yang digunakan layak atau tidak dan berdasarkan penelitian yang telah kami lakukan, maka hasil perhitungan analisis kelayakan financial Usaha Pengolahan Kerupuk Ikan dilihat dari kriteria kelayakan usaha dapat dilihat pada table berikut. 
Hilir Kabupaten Seruyan.

\begin{tabular}{|l|l|l|}
\hline No & \multicolumn{1}{|c|}{ Kriteria Kelayakan } & Nilai \\
\hline 1 & Net Present Value (NPV) (Rp) & Rp 192.357.299,43 \\
\hline 2 & Internal Rate of Return (IRR) (\%) & $60,94 \%$ \\
\hline 3 & Net Benefit Cost Ratio (Net B/C) & 2,76 \\
\hline 4 & Payback Period & 3 tahun 18 hari \\
\hline
\end{tabular}

Sumber: Data Primer(diolah), 2018.

Penghitungan didasarkan pada nilai rata-rata pendapatan yang diperoleh oleh 18 pengrajin kerupuk ikan yang ada di Kecamatan seruyan Hilir, dan seperti yang sudah di uraikan sebelumnya, hasil perhitungan dengan kriteria investasi merupakan salah satu cara untuk menilai apakah usaha yang dijalankan layak atau tidak dan berdasarkan hasil yang di peroleh dari 4 kriteria investasi, yang pertama nilai Net Present value (NPV) yang diperoleh dari usaha pengolahan kerupuk ikan adalah sebesar Rp 192.357.299,43, hal ini berarti bahwa usaha pengolahan kerupuk ikan layak untuk dilanjutkan, karena laba dimasa depan lebih tinggi dari pada biaya yang digunakan pada masa sekarang (Hopkins, 2016).

Ukuran kedua dengan melihat nilai Internal Rate of return (IRR) yang digunakan untuk menghitung tingkat suku bunga yang menyamakan nilai sekarang investasi dengan nilai sekarang, dan menurut Gittinger (1986) suatu investasi dianggap layak apabila memiliki IRR lebih besar dari tingkat suku bunga yang berlaku dan suatu investasi dianggap tidak layak apabila memiliki nilai IRR yang lebih kecil dari tingkat suku bunga yang berlaku, nilai Internal Rate of return (IRR) dari usaha kerupuk ikan di kecamatan seruyan hilir sebesar 60,94\%, hal ini mengindikasikan nilai IRR lebih besar dari Social Opportunity Cost of Capital (SOCC) yang digunakan, dalam hal ini SOCC yang digunakan sebesar 17,5\% (kredit mikro Bank Mandiri) yang berarti usaha pengolahan kerupuk ikan di Kecamatan Seruyan hilir layak untuk di usahakan.

Net benefit cost ratio (Net $B / C$ ), adalah criteria ketiga yang digunakan dalam penelitian ini, untuk menilai layak tidak nya usaha yang dijalankan dimana jika nilai Net B/C lebih dari 1, yang berarti setiap satu rupiah yang dikeluarkan akan mendapat atau menghasilkan manfaat bersih melebihi tambahan biaya yang dikeluarkan, dan berdasarkan penelitian yang telah dilakukan maka nilai Net B/C yang diperoleh sebesar 2,75 yang berarti lebih besar dari 1 dan mengindikasikan usaha 
pengolahan kerupuk yang di lakukan layak untuk dikerjakan.

Pay Back Period yang merupakan jangka waktu yang digunakan untuk menilai pengembalian modal dalam suatu usaha, atau untuk mengetahui berapa lama usaha yang dijalankan baru dapat mengembalikan investasi (Ibrahim, 2009). Pada usaha pengolahan kerupuk ikan ini pay back period yang diperoleh 3 tahun 18 hari, dan ini merupakan waktu yang cukup lama untuk pengembalian modal usaha, karena semakin cepat pengembalian biaya investasi, maka akan makin cepat juga perputaran modal untuk keberlangsungan usaha yang dijalankan.

Berdasarkan hasil dari empat kriteria yang digunakan, maka usaha pengolahan kerupuk ikan di Kecamatan Seruyan Hilir layak untuk dilanjutkan. Usaha pengolahan kerupuk ikan ini juga memberikan manfaat dari segi keuntungan yang diperoleh oleh para pengrajin yang mengusahakan pengolahan kerupuk ikan di kecamatan seruyan hilir, sehingga usaha yang mereka jalankan mampu bertahan.

\section{Analisis switching value (Analisis sensitifitas)}

Hasil analisis switching value dengan menggunakan parameter 1 yaitu terjadi kenaikan harga bahan baku pengolahan kerupuk ikan sebesar 5\%, $10 \%$ dan $15 \%$ dapat di lihat pada tabel 5 berikut ini:

Tabel 5. Parameter 1 Terjadi Kenaikan Harga Bahan Baku Naik 5\%, 10\% dan 15\%

\begin{tabular}{|c|c|c|c|c|}
\hline No & $\begin{array}{c}\text { Kriteria } \\
\text { Kelayakan }\end{array}$ & $5 \%$ & $10 \%$ & $15 \%$ \\
\hline 1 & $\begin{array}{l}\text { Net Present Value } \\
\text { (NPV) (Rp) }\end{array}$ & Rp 166.209.868,32 & Rp 140.062.437,22 & Rp 113.915.006,11 \\
\hline 2 & $\begin{array}{l}\text { Internal Rate of } \\
\text { Return (IRR) }(\%)\end{array}$ & $52,56 \%$ & $45,23 \%$ & $37.71 \%$ \\
\hline 3 & $\begin{array}{l}\text { Net Benefit Cost } \\
\text { Ratio }(\mathrm{Net} \mathrm{B} / \mathrm{C})\end{array}$ & 2,52 & 2,28 & 2,04 \\
\hline 4 & $\begin{array}{ll}\text { Payback } & \text { Period } \\
\text { (Bulan) } & \end{array}$ & 3 tahun 2 bulan 7 hari & 3 tahun 4 bulan 14 hari & 4 tahun 2 bulan 19 hari \\
\hline
\end{tabular}

Sumber: Data Primer(diolah), 2018.

Berdasarkan hasil table 5 di atas usaha pengolahan kerupuk ikan masih layak diusahakan walaupun terjadi kenaikan harga bahan baku sampai 15\%, namun dilihat dari segi pengembalian modal atau pay back period kenaikan bahan baku memberi pengaruh pada jangka waktu yang lebih lama, sehingga akan memperlambat masa pengembalian modal yang digunakan sebagai investasi awal usaha. 
Tabel 6. Parameter 2 Terjadi Penurunan Harga Jual kerupuk 5\%, 10\% dan 15\%

\begin{tabular}{|c|l|c|c|c|}
\hline No & \multicolumn{1}{|c|}{ Kriteria Kelayakan } & $\mathbf{5 \%}$ & $\mathbf{1 0 \%}$ & $\mathbf{1 5 \%}$ \\
\hline 1 & Net Present Value (NPV) (Rp) & Rp 148.413.789,66 & Rp 104.470.279,89 & Rp 99.771.895,78 \\
\hline 2 & $\begin{array}{l}\text { Internal Rate of Return (IRR) } \\
(\%)\end{array}$ & $\begin{array}{l}47,59 \% \\
\text { B/C) }\end{array}$ & 2,36 & 1,96 \\
\hline 4 & Payback Period (Bulan) & $\begin{array}{l}3 \text { tahun 9 bulan 1 } \\
\text { hari }\end{array}$ & 4 tahun 4 bulan & 5 tahun 5 bulan 4 hari \\
\hline
\end{tabular}

Sumber: Data Primer(diolah), 2018.

Penurunan harga jual pada parameter kedua mengindikasi bahwa penurunan harga jual lebih sensitive dibandingkan dengan kenaikan bahan baku, hal ini sejalan dengan penelitian Winarti L, 2016 bahwa penurunan harga jual lebih sensitive dibandingkan dengan penurunan harga bahan baku dalam pengolahan kerupuk ikan pipih, dan hal ini bisa terlihat pada sensitifitas $15 \%$ pay back period menjadi lebih lama waktunya yaitu 5 tahun 5 bulan 4 hari. Hasil analisis switching value batas maksimum kenaikan harga bahan baku adalah sebesar $37,80 \%$ dan batas penurunan harga jual kerupuk sebesar 24,30\% (Tabel 8).

Tabel 7. Analisis Sensitivitas

\begin{tabular}{|l|c|}
\hline \multicolumn{1}{|c|}{ Parameter } & Nilai (\%) \\
\hline Kenaikan harga bahan baku tertinggi & 37,80 \\
\hline Penurunan harga jual kerupuk terendah & 24,30 \\
\hline
\end{tabular}

Sumber: Data Primer(diolah), 2018.

Bahan baku merupakan bahan utama dalam usaha pengolahan kerupuk ikan dan dalam usaha pengolahan kerupuk ikan ini, batas tertinggi dan masih di katakana layak kenaikan bahan baku adalah sebesar $37,80 \%$ dan untuk penurunan harga jual kerupuk terendah sebesar 24, 30\% dengan harga jual Rp60.600. Peningkatan bahan baku dan penurunan harga jual pada batas terntentu (tabel 7) pada usaha kerupuk ikan akan menyebabkan usaha yang dijalankan menjadi lebih lama dalam pengembalian investasinya, ditambah lagi pemasaran produk tidak terlalu luas dan banyak yang mengusahakan usaha yang sejenis, selain itu juga untuk meningkatkan harga jual dari kerupuk menjadi hal yang agak sulit apalagi untuk usaha-usaha industri pengolahan kerupuk yang terbilang baru akan kalah bersaing dengan pengrajin kerupuk yang sudah turun temurun.

\section{Model Pengembangan Usaha Entrepreneurial Marketing)}

Hasil pengujian model pengukuran pada pengembangan usaha kerupuk ikan dengan menggunakan SmartPLS3 seperti pada gambar 2. Menunjukkan bahwa ada 7 variabel indicator (pro2, pro3, pu2, pu7, pu8, pu6, dan pu1) yang memiliki nilai loading 
factor kurang dari 0,6, dan untuk nilai loading factor yang dapat ditoleransi dalam penelitian yang bersifat explanatory antara 0,6-0,7 (Ghozali dan
Latan. 2015), sehingga nilai variable yang kurang dari 0,6 akan di hapus dari model untuk dapat melakukan uji hipotesis pada penelitian.

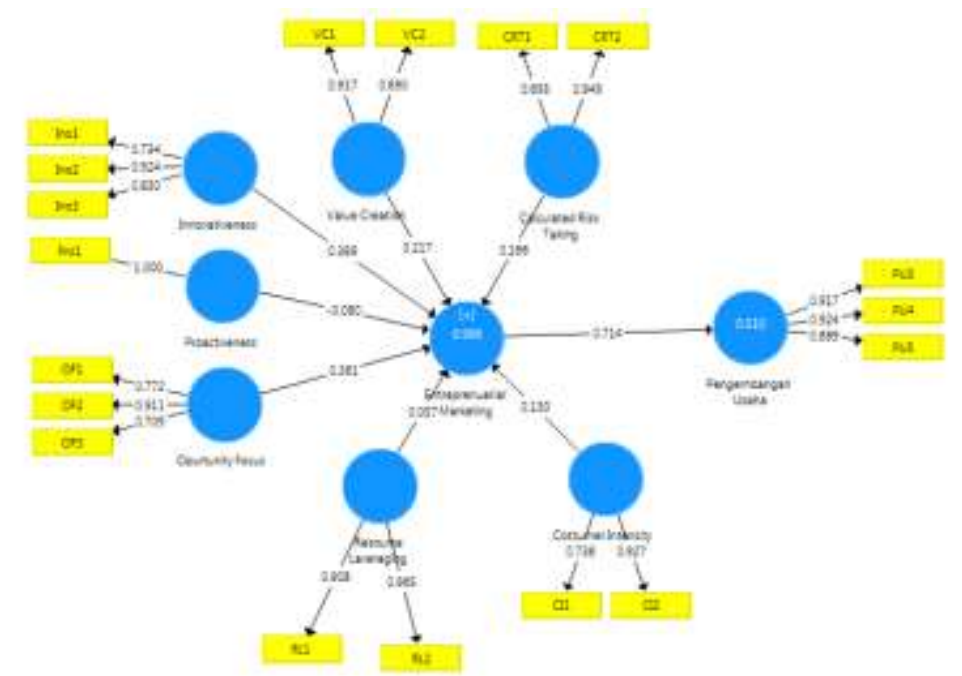

Gambar 2. Hasil Pengujian Model Pengukuran

Sumber: Data Primer(diolah), 2018.

Convergent validity merupakan reliable, dan pada nilai Avarage cara lain, selain dari nilai loading factor Variance Extracted ( $A V E$ ) yang memiliki untuk melihat nilai validitas dan nilai 0,318, dan menurut Fornell dan realiabilitas pada masing-masing criteria pengujian nyang digunakan. Convergent validity dapat dilihat dari nilai Avarage Variance Extracted ( $A V E$ ), adapun nilai realiabilitas baik menggunakan cronbachs Alpha maupun Convergent validity masing-masing konstruk Larcker (1981) jika nilai AVE kurang dari 0,5 , tetapi nilai composite lebih tinggi dari 0,6 dan Convergent Validity dari konstruk masih mencukupi realibility, karena tidak ada masalah dalam Convergent Validity pada model melebihi 0,7 sehingga dapat dikatakan Tabel 8. Hasil Analisis beberapa Kriteria Pengujian Model Pengukuran

\begin{tabular}{|l|c|c|c|c|}
\hline Variabel & Cronbachs Alpha & Composite Realiability & AVE & Akar AVE \\
\hline Calculate risk taking & 0,603 & 0,814 & 0,691 & 0,887 \\
\hline Costumer Intensity & 0,602 & 0,823 & 0,702 & 0,744 \\
\hline Entrepreneurial Marketing & 0,781 & 0,835 & 0,318 & 0,873 \\
\hline Innovativeness & 0,777 & 0,871 & 0,694 & 0,798 \\
\hline Opportunity Focus & 0,717 & 0,842 & 0,634 & 0,735 \\
\hline Pengembangan Usaha & 0,898 & 0,935 & 0,828 & 0,931 \\
\hline Proactiveness & 1,000 & 1,000 & 1,000 & 1,000 \\
\hline Resourse Laveranging & 0,867 & 0,935 & 0,878 & 1,003 \\
\hline Value Creation & 0,776 & 0,899 & 0,816 & 0,786 \\
\hline
\end{tabular}

Sumber: Data Primer(diolah), 2018. 
Mengevalusi hasil output

SmartPLS3.0 terhadap model structural dengan melihat nilai estimasi dari koefisien jalur meliputi pengaruh nyata suatu konstruk laten dengan konstruk laten lainnya, pada bootstrapping untuk dapat melihat pengaruh langsung, dan nilai T-statistik sebagai dasar dalam menilai pengaruh signifikan suatu konstruk. Pengujian hipotesis menggunakan metode Bootstrapping pada aplikasi SmartPL diketahui bahwa ada 3 variabel pembentuk Entrepreneurial marketing, yaitu ikatan Innovativeness terhadap Entrepreneurial marketing, Oppurtunity Focus terhadap Entrepreneurial marketing dan value Creation terhadap entrepreneurial marketing dan semuanya berpengaruh signifikan, hal ini dapat dilihat dari nilai $\mathrm{t}$ hitung pada Tabel 8.

Innovativeness terhadap Entrepreneurial marketing memiliki pengaruh yang sangat nyata dengan $p$ value 0,000, dengan menciptakan inovasi yang dilakukan pengrajin terhadap kerupuk ikan yang dibuatnya, mulai dari rasa, berat kerupuk yang dikemas, tampilan kemasan, cita rasa kerupuk yang tentu saja semua inovasi yang dilakukan sesuai dengan keinginan konsumen dan untuk pengembangan usaha yang dilakukan, menurut Wang \& Ahmed (2004) inovasi sebagai keseluruhan kemampuan inovatif organisasi untuk memperkenalkan produk baru ke pasar, atau membuka pasar baru, hal ini sejalan dengan Van de Vrande et al., 2009 Inovasi telah menjadi sangat penting sebagai prasyarat untuk keunggulan kompetitif dan kelangsungan hidup perusahaan. Dan inovasi tampaknya vital untuk perusahaan wirausaha kecil dengan sumber daya terbatas. Inovasi adalah hal yang kritis penentu kinerja bisnis (Cooper, 2000). Dengan Entrepreneurial Marketing menjadi fungsi pemasaran memainkan peran bagian integral dalam inovasi yang berkelanjutan untuk mepertahankan eksistensi dari suatu usaha 
Tabel 9. Hasil Bootstrapping pada Model Struktural.

\begin{tabular}{|c|c|c|c|c|c|}
\hline Variabel Laten & $\begin{array}{l}\text { Original } \\
\text { Sampel } \\
\text { (O) }\end{array}$ & $\begin{array}{l}\text { Sampel } \\
\text { Mean } \\
\text { (M) }\end{array}$ & $\begin{array}{l}\text { Standar } \\
\text { Deviasi }\end{array}$ & $\begin{array}{l}\text { T Statistic } \\
\text { (IO/STDEV) }\end{array}$ & P value \\
\hline $\begin{array}{l}\text { Calculated Risk Taking } \rightarrow \text { Entrepreneurial } \\
\text { Marketing }\end{array}$ & 0,166 & 0,165 & 0,094 & 1,762 & 0,079 \\
\hline $\begin{array}{lll}\begin{array}{l}\text { Costumer } \\
\text { Marketing }\end{array} & \text { Intensity } \rightarrow & \text { Entrepreneurial } \\
\end{array}$ & 0,130 & 0,107 & 0,085 & 1,533 & 0,126 \\
\hline $\begin{array}{ll}\text { Entrepreneurial } & \text { Marketing } \rightarrow \\
\text { Pengembangan Usaha } & \end{array}$ & 0,714 & 0,750 & 0,122 & 5,873 & 0,000 \\
\hline $\begin{array}{ll}\text { Innovativeness } \rightarrow & \text { Entrepreneurial } \\
\text { Marketing } & \end{array}$ & 0,389 & 0,353 & 0,085 & 4,569 & 0,000 \\
\hline $\begin{array}{l}\text { Opportunity } \\
\text { Marketing }\end{array}$ & 0,361 & 0,320 & 0,102 & 3,537 & 0,000 \\
\hline $\begin{array}{lll}\text { Proactiveness } & \rightarrow & \text { Entrepreneurial } \\
\text { Marketing } & & \\
\end{array}$ & $-0,080$ & $-0,070$ & 0,116 & 0,685 & 0,494 \\
\hline $\begin{array}{l}\text { Resourse Laveranging } \rightarrow \text { Entrepreneurial } \\
\text { Marketing }\end{array}$ & 0,057 & 0,065 & 0,101 & 0,562 & 0,575 \\
\hline $\begin{array}{lll}\begin{array}{l}\text { Value Creation } \\
\text { Marketing }\end{array} & \rightarrow & \text { Entrepreneurial } \\
\end{array}$ & 0,217 & 0,189 & 0,075 & 2,878 & 0,004 \\
\hline
\end{tabular}

Keterangan:*signifikan pada $\alpha 0,05 * *$ signifikan pada $\alpha 0,01$

Sumber: Data Primer(diolah), 2018.

Variabel lainnya yang berpengaruh terhadap Entrepereneurial Marketing adalah Oppurtunity Focus yang memiliki nilai yang sangat signifikan ( $p$ value 0,000), upaya dalam mencari pangsa pemasaran kerupuk ikan yang baru yang dilakukan untuk memperluas aspek pemasaran sebelum pesaing produk yang sejenis, dan memaksa pengusaha kerupuk ikan harus lebih aktif dalam memasarkan kerupuk ikan yang mereka produksi, baik melalui pameran-pameran yang diadakan ditingkat kabupaten sampai tingkat propinsi, hal ini dilakukan untuk memperkenalkan produk mereka ke konsumen. Mengingat munculnya pesaing baru usaha yang sejenis, menyebabkan pengusaha kerupuk ikan harus lebih aktif dalam mencari peluang pasar baru, Morris et al (2002) posisi pasar yang tidak diperhatikan yang merupakan sumber potensi keuntungan yang berkelanjutan dan eksploitasi peluang memerlukan pembelajaran dan adaptasi berkelanjutan oleh pemasar sebelum, selama, dan setelah yang sebenarnya implementasi konsep yang inovatif.

Ikatan value creation terhadap Entrepreneurial Marketing, memiliki nilai yang sangat signifikan pada p-value 0,004, untuk dapat mempertahankan usahanya pengrajin kerupuk ikan yang berada di kecamatan seruyan hilir harus mampu menciptakan nilai untuk perbaikan pada usahanya, dan ini yang dilakukan oleh pengrajin kerupuk ikan untuk membuat usaha kerupuk ikan yang mereka lakukan tetap bertahan, meskipun banyak pesaingpesaing baru bermunculan. 


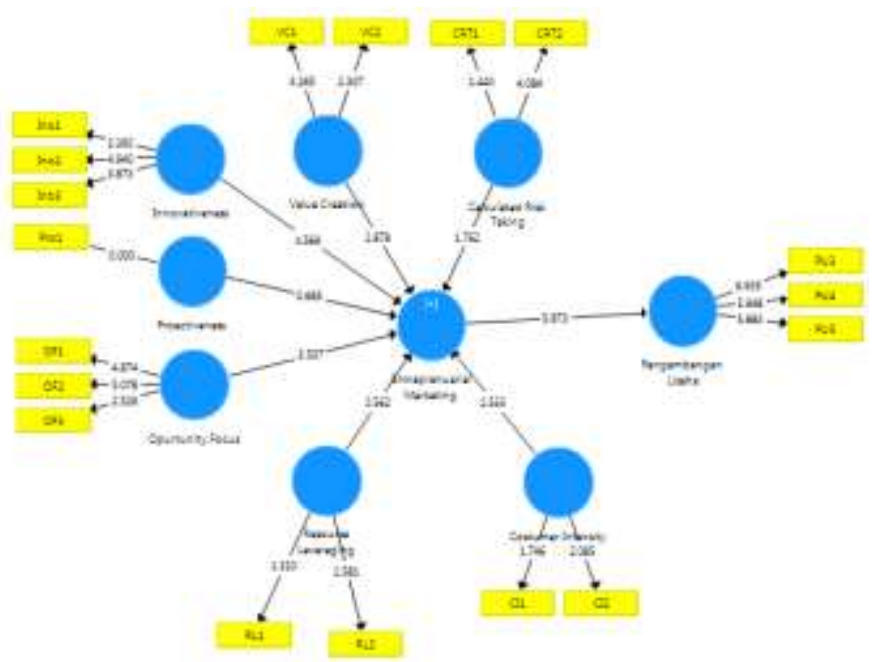

Gambar 3. Hasil Pengujian Model Struktural Sumber: Data Primer(diolah), 2018.

\section{Entrepreneurial}

terhadap pengembangan usaha berpengaruh sangat signifikan dengan nilai 0,000 yang didasarkan pada keinginan pelaku usaha untuk mengembangkan usahanya dengan memanfaatkan peluang yang terbentuk beberapa variable yang signifikan Innovativeness, Oppurtunity Focus dan Value Creation yang membentuk Entrepreneurial Marketing, dan di dalam Entrepreneurial Marketing (Sarma, 2013) refleksi dan sikap proaktif pelaku usaha dalam mengidentifikasi dan mengeksploitasi berbagai peluang untuk mendapatkan dan mempertahankan usaha melalui berbagai inovatif, pengelolaan risiko, pengoptimalan sumberdaya, penciptaan nilai tambah, hingga menjaga hubungan dengan stakeholder melalui berbagai karekteristik wirausaha sebagai konsep dasarnya, hal ini dilakukan oleh pelaku usaha agar dapat mempertahan kan usaha yang dilakukannya. Dalam mengembangkan usahanya pengrajin kerupuk ikan di Kecamatan Seruyan Hilir tidak kesulitan dalam memperoleh bahan baku ikan sebagai bahan baku utama dalam pengolahan kerupuk ikan, namun disisi lain komunikasi yang baik dengan pemasok harus tetap dijaga untuk kelancaran dalam produksi kerupuk ikan, mengingat usaha kerupuk ikan adalah usaha yang mudah di ikuti oleh pesaing baru yang ingin mencoba berusaha usaha yang serupa.

Selain kemudahan dalam memperoleh bahan baku utama yaitu ikan, untuk pengembangan usaha pengrajin kerupuk perlu membuka pasar online tersendiri bagi produk kerupuk ikan yang dihasilkan untuk menjangkau pangsa pasar yang lebih luas, hal ini 
sejalan dengan Pemadi, R (2018) di jaman modern sekarang informasi sangat terbuka, sehingga tidak terlalu sulit untuk mengakses segala informasi yang berkaitan dengan pasar dan ini merupakan salah satu strategi inidividu dalam meningkatkan kekuatan pasar, dengan meningkatkan akses dari produsen langsung ke konsumen, sehingga produk kerupuk ikan yang di produksi menjadi lebih dikenal di kalangan masyarakat.

\section{KESIMPULAN}

Berdasarkan tujuan dan hasil pembahasan pada penelitian ini, maka dapat disimpulkan bahwa: Analisis kelayakan usaha kerupuk ikan berdasarkan 4 criteria investasi yang digunakan pada usaha pengolahan kerupuk ikan di kecamatan seruyan hilir layak untuk dilanjutkan. Selanjutnya pada analisis sensitifitas pada usaha pengolahan kerupuk ikan ternyata penurunan harga jual lebih sensitive jika dibandingkan dengan penurunan harga bahan baku, dan untuk kenaikan harga bahan baku batas tertinggi sebesar $37,80 \%$ dan untuk penurunan harga jual kerupuk batas terendah sebesar 24,30\%. Berdasarkan analisis model pengembangan usaha (Entrepreneurial Marketing) diketahui bahwa
Entrepreneurial marketing berpengaruh sangat signifikan ( $p$ value 0,000 ) terhadap pengembangan usaha kerupuk ikan di Kecamatan Seruyan Hilir Kabupaten Seruyan.

\section{DAFTAR PUSTAKA}

Badan Pusat Statistik. 2017. Seruyan Dalam Angka. BPS. Kabupaten Seruyan. Kalimantan Tengah.

Cooper, R.G and Kleinsschmidt, E.J (2000). New Product performance what distinguishes the star product" Australian Journal of a Management. 25(1) 17-45.

Dinas Kelautan dan Perikanan (DISLUTKAN). 2017. Laporan Tahunan 2016. Kabupaten Seruyan. Kalimantan Tengah.

Dinas Koperasi, UKM, Perindustrian dan Perdagangan. 2017. Kabupaten Seruyan Kalimantan Tengah.

Fornel and Larcker. 1981. Evaluating Structural Equation Models with Unobservable Variables and Measurement Error. Jurnal of Narketing Reaserch vol. 18 no.1(feb 1981), pp 39-50. American Marketing Association.

Gittinjer P. 1986. Analisis Ekonomi Proyek-Proyek Pertanian. Jakarta: UI Press.

Ghozali A. 2015. Partial Least Square. Konsep, Teknik dan Aplikasi Menggunakan Program SmartPLS 3.0. Untuk Penelitian Empiris. Badan Penerbit UNDIP. Semarang. 
Hopkins. M. 2016. The Case for Project Net Present Value (NPV) and NPV Risk Models. PM World Journal 5(6).

Ibrahim Y. 2002. Studi Kelayakan Bisnis. Jakarta: Rineka Cipta.

Morris HM, Schindehutte M \& LaForge RW. 2002. Entrepreneurial Marketing: A Construct For Integrating Emerging Entrepreneurship And Marketing Perspectives. Journal of Marketing Theory and Practice. Vol. 10, No. 4.

Permadi, R dan Winarti, L. 2018. The Analysis of Factors Affecting Farmers Accescibility Towards Markets and its Relation to Farmers. Journal Management of Agribusinnes. IPB. Link Journal http://jai.ipb.ac.id/index.php/jmag r/article/view/18037.

Sarma. M. 2013. Entrepreneurial Marketing untuk keberhasilan Pemasaran bagi Usaha Mikro, Kecil, Menengah (UMKM) Indonesia. Bogor (ID): IPB Press.
Van De Vrende et al. 2009. Open Innovative in SMEs:trends, motives ang management challenges, Technovation 29 (2009) 423-437.

Winarti, L. 2016. Analisis Sensitivitas Usaha Pengolahan Kerupuk Ikan Pipih di Kecamatan Seruyan Hilir Kabupaten Seruyan. Zira'ah Majalah Ilmu Pertanian Vol. 41 no.2, hal 177-182. Link jurnal https://ojs.uniska-

bjm.ac.id/index.php/ziraah/article/ view/418.

Wang, Catherine L, Ahmed, Pervaiz K. 2004. The Development and Validation of the Organization Innovativennes Construk Using Confirmatory Factor Analysis. Europan Journal Of Innovation Management. 7(4) Desember 2004. 